\title{
Suppressing Competition in a Computer-Supported Collaborative Learning System
}

\author{
Kwangsu Cho and Bosung Kim \\ 221A Townsend Hall, School of Information Science \& Learning Technologies, \\ University of Missouri, Columbia, MO 65211, USA \\ chokw@missouri.edu, bkq22@mizzou.edu
}

\begin{abstract}
The purpose of this study is to explore how student competition using the tit-for-tat strategy could be remedied with a minimum design change in order to support student to collaborate constructively in a computer supportedcollaborative learning system called SWoRD (Scaffolded Writing and Reviewing in the Discipline) [5], a reciprocal peer reviewing of writing system. We identified a factor for the tit-for-tat that causes learners to compete each other, and removed the factor from the interface. The results show when with the interface improvement the tit-for-tat strategy was restrained in the SWoRD system, which helped the learners constructively respond to peer comments.
\end{abstract}

Keywords: Collaborative learning, Peer review of writing, competition, SWoRD, peer evaluation.

\section{Introduction}

When collaborative learning is implemented, researchers and practitioners expect learners to work collaboratively, to help each other, and to enhance their learning. In reality, however, learners do not always work collaboratively in collaborative learning environments [8] and sometimes they are emotionally charged and compete with each other [15]. This unfortunate situation is very likely to happen in reciprocal peer reviewing of writing, a special type of collaborative learning situations, where student writing is graded and commented by multiple peers instead of instructors [5].

Anecdotal evidence raised the concern about the competition that may damage the use and learning effects of the computer supported collaborative learning (CSCL) system, especially when the system is being used in real settings where learners' activities account for their final grades. Consistently, Rushton, Ramsey, and Rada [18] found that competition among learners might bring up negative perception about the system and made them reject the use of the system.

Therefore, in this study we investigate the competition among learners in a CSCL environment where the learners are expected to help each other for their learning by generating constructive comments on peers' writing and exchange unbiased grades. We designed simple interfaces to remedy this unfortunate situation, and test them with large-scale empirical data collected from 18 courses, three universities located in the U.S. 


\section{Literature Review}

\subsection{Peer Review of Writing}

Although peer review is ubiquitous in first-year composition courses in universities in the U.S., its practical and theoretical values are rarely investigated $[6,12]$. Peer review is practically an important solution in writing education because instructors are simply overwhelmed by the workload of reading, commenting on, and grading student papers, and also in part because some instructors see peer review as an essential practice.

Peer review of writing can provide student authors with valuable suggestions that can be used to improve weakness of the draft of writing in a timely manner [5]. To reviewers, this reviewing practice provides opportunities to criticize peers' work based on given criteria and therefore reviewers become more aware of the requirements of tasks and more responsible for their own learning. Earlier studies done by Falchikov [11] and McDowell [17] reported that peer review helps students become more independent, critical, and reflective on their learning. In particular, when multiple reviews are used, students may practice multiple writing with timely feedback [6]. Also it was found that peer reviews are very reliable and as valid as instructor reviews [9].

\subsection{Issues with Peer Review}

Although the benefits of peer review on student learning are obvious, there have been issues that need to be resolved in order to make this strategy implemented successfully for student learning. One of the most serious issues is to improve students' trust on peer reviewing. It is highly likely that students may not favor or have concern on peer review in part because experts/instructors are the most typical source of reviewing on student writing, and also in part because students are novices in their disciplines [5]. Consistently, several studies found that some students did not have a faith in peers' abilities as a reviewer and wanted for feedback from more authority figure such as lecturers [17] or they felt peer reviewers as competitors [16]. Lin et al [16] found that upon receiving low scores from peers via a Web-based two-way anonymous peer assessment system, students often revenged each other by reducing the previous scores they gave to other students.

Therefore, the competition among student participants may undermine the acceptability of a computer supported collaborative learning environment, which in turn may lead to poor learning outcomes. Recently Cho, Schunn, and Wilson [9] found an interesting aspect on how students perceive peer reviews differently from instructors when the students receive good quality of peer reviews. They found that even if peer reviews are reliable and valid from the instructor's perspective, they could be perceived as unreliable and invalid from the students' perspective. Thus, regardless of the objective quality of peer reviews, students may be seriously concerned about peer evaluations. Consistently, Topping, Smith, Swanson, and Elliot [20] wrote, "acceptability to students is various and does not seem to be a function of actual reliability" (p. 152).

Computer-supported peer review systems may deepen the severity of the issue. While anonymity implemented in peer review systems help students free from face 
pressure and thus become more critical, anonymity may also cause low quality of peer review [21] that may create a vicious cycle of chipping away collaboration. For example, Zhao [21] created anonymity through a mail distribution system and studied whether anonymity influences their peer reviewing activity. As expected, the students were sensitive to each other in the anonymous condition rather than in the onymous condition.

\subsection{Conditions for Peer Review}

Recently, Cho, Schunn, and Kwon [7] proposed a new theory called Learning Writing By Reviewing showing that student reviewers learn writing skills by reviewing others' work. The Learning Writing By Reviewing theory goes beyond peer reviewing as a practical solution. To fully benefit from peer reviewing, students should perceive peer review to be valuable activities for their own learning. Otherwise, they will not be able to benefit from this strategy.

Social interdependence theory $[13,14]$ argues that a cooperative learning environment should promote positive interdependence among participants. When learning conditions are structured cooperatively, individuals are more willing to give and receive constructive feedback while they are not when learning conditions are structured competitively. By contrast, in a competitive learning environment where students perceive others' failure as their success and vice versa, they are highly likely to perceive peers as opponents, not to trust feedback from peers, and to be emotionally charged when they receive poor grade.

\subsection{The Purpose of the Study}

The research question is the role of interfaces we design for controlling competition among learners in a CSCL environment. We examined the question in SWoRD [2, 3, $4,5]$, a hybrid intelligent system of implementing reciprocal peer reviewing of writing where participants exchange grades and comments. In SWoRD, each student plays two roles, one of writer and one of reviewer. Student reviewers are expected to help peer writers with constructive comments, whereas writers are asked to provide the peer reviewers with back-reviews, writers' evaluations on reviewers' comments in terms of how helpful the comments were in revising their writing.

The design problem in this research concerns that although back-reviews are designed to improve reviewers' feedback skills, some students take advantage of backreviews to retaliate peer reviewers who gave the writers low scores. This behavior is called the tit-for-tat strategy widely known in game theory [1] that an individual reacts to an opponent by repeating the opponent's action. Thus, writers return high grades to peer reviewers who give high scores or give low scores to those who give low ratings. Although peer reviewing of writing has found to be as effective as or even superior than instructor assessment in terms of writing improvement $[9,19]$, this tit-for-tat strategy may undermine the utility of peer review.

To address the issue, we developed two different interfaces for dealing with the titfor-tat strategy between collaborators as shown in Figure 1. One interface displayed individual peer ratings along with written comments to a writer. This interface is called emotional interface because when students receive individual peer ratings, 
students may take written comments with individual ratings personally. Students may pay more attention to the grade awarded rather than reading feedback [17]. As Crampton [10] warned, students would show strong emotional reactions when they take task-oriented critiques personally. The other interface is called cognitive interface showing only written comments without individual peer ratings. The cognitive interface may help writers focus on written comments without being interrupted by evaluation scores. Therefore, it was expected to find a higher correlation between peer review ratings and writers' back-reviews with the emotional interface than with the cognitive interface.
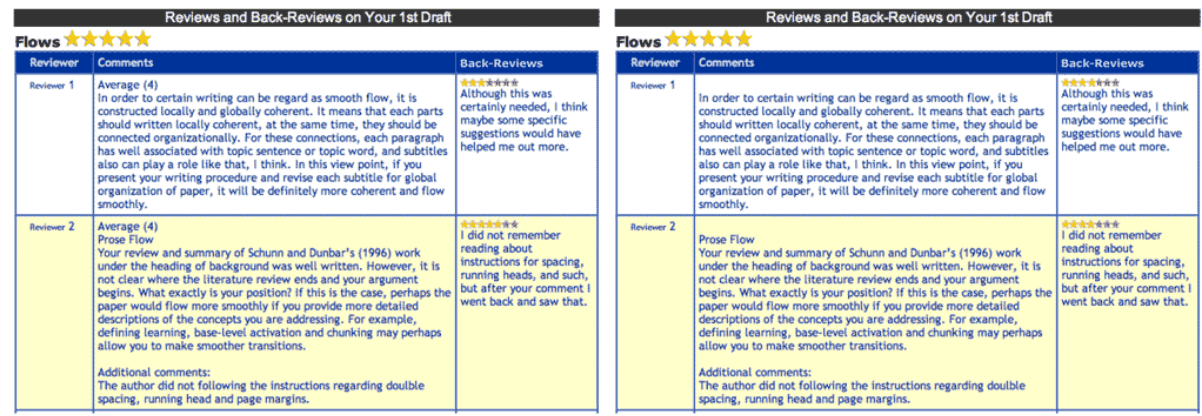

Fig. 1. Example screenshots of emotional interface (left) and cognitive Interface (right) for authors. Note that the individual peer ratings from each reviewer are not shown to writers in the cognitive interface.

\section{Method}

\subsection{Participants}

Data were collected from three universities located in the U.S from Spring 2004 to Spring 2006. 617 students across 18 different courses participated in the research. All courses used the SWoRD system for their course credits. Typically writing and reviewing together accounted for approximately $40 \%$ of the final course grade. The required length of the assigned papers varied from shorter (5-to-8 pages) to longer papers (10 to 15 pages).

\subsection{Context of the Study}

In SWoRD, students under pseudonyms submitted their draft papers and self-evaluated the quality of their draft on a 7-point scale (1: Disastrous to 7: Excellent). Then, the system distributed papers to peer reviewers. Peer reviewers reviewed each draft by providing detailed written comments on each three dimensions of the given rubric and then rated each draft on the 7-point scale. After this process, each writer received written comments with ratings via the emotional interface or without ratings via the cognitive interface. The writers revised their draft and did back-reviews with which they 
rated the helpfulness of each peer review on the scale. Peer review scores and helpfulness scores generated during this process were reflected in their final grading.

\section{Results and Discussion}

To investigate the impact of the emotional and cognitive interface to deal with the titfor-tat strategy, Pearson correlation analyses were conducted separately for each group of students: the emotional interface group vs. the cognitive interface group. The correlation matrix in Table 1 shows that, for the emotional interface group the backreviews were positively correlated with peer ratings, $r(1751)=.32, p<.01$. By contrast for the cognitive interface group a significant correlation did not appear, $r(815)$ $=.06, p>.05$. This indicates that students, who received individual peer rating via the emotional interface, were more likely to use the tit-for-tat strategy, while the cognitive interface suppressed the strategy use, which in turn led to focus on the use of written comments.

Table 1. Correlation coefficients among self-evaluations, individual peer ratings, back-reviews in the emotional interface group $(n=1752)$ and cognitive interface group $(n=816)$

\begin{tabular}{lccc}
\hline & Self-Evaluation & Peer Review Rating & Back-Reviews \\
\hline Emotional Interface Group & & & \\
$\quad$ Self-Evaluation & - & & \\
Individual Peer Ratings & $.28^{* *}$ & - & - \\
Back-Reviews & $.12^{* *}$ & $.32^{* *}$ & 5.46 \\
Mean & 5.68 & 5.38 & 1.10 \\
SD & .91 & 1.09 & \\
Cognitive Interface Group & & & - \\
$\quad$ Self-Evaluation & - & & 4.88 \\
Individual Peer Ratings & $.15^{* *}$ & - & 1.70 \\
$\quad$ Back-Reviews & .05 & .06 & \\
Mean & 5.75 & 5.56 & \\
SD & .82 & 1.03 & \\
\hline$* * p<.01$ & & &
\end{tabular}

\section{Conclusion}

The goal of this paper was to share the design decision that how the SWoRD system suppressed the use of the tit-for-tat strategy that may undermine effective collaboration among participants who are supposed to help each other. This study found that the tit-for-tat strategy use was restrained when individual peer ratings were removed from the interface of SWoRD. It is important to note that when students take peer review personally and emotionally, they may not be willing to use peer feedback to improve their work. The cognitive interface of SWoRD would create a better collaborative environment where student writers are more likely to act upon written comments than the emotional interface. 
However, there is still a possibility that students might be emotionally charged by critical and negative written comments. For example, student reviewers might use unnecessary flaming expressions. Further studies on interface design may need to focus on this issue. It would be also interesting to see what types of written feedback students perceive the most helpful and how we could design a constructive environment where reviewers generate helpful comments.

Acknowledgments. This research was supported by the grants from the Andrew Mellon Foundation, the University of Pittsburgh Provost Office, and the Korea Education Research and Information Service to the first author.

\section{References}

1. Cho, K., Schunn, C.D.: Strategy Shift in Prisoner's Dilemma Through Utility Learning. Paper presented at the 9th Annual ACT-R Workshop. Carnegie Mellon University, Pittsburgh PA (2002)

2. Cho, K., Schunn, C.D.: Battling the Tyranny of the Thousands with a SWoRD: Scaffolded Writing and Rewriting in the Discipline. In: Proceedings of ED-Media 2003. Honolulu Hawaii USA (2003)

3. Cho, K., Schunn, C.D.: The SWoRD is Mightier than the Pen: Scaffolded Writing and Rewriting in the Discipline. In: Proceedings of IEEE International Conference on Advanced Learning Technologies. Joenssu Finland (2004)

4. Schunn, C.D., Cho, K.: Examining Student Reflections on the Many Opportunities to Learn in Reciprocal-Evaluation Writing Settings. In: Proceedings of 11th Biennial Conference of EARLI (European Association for Research on Learning and Instruction). Nicosia Cyprus (2005)

5. Cho, K., Schunn, C.D.: Scaffolded Writing and Rewriting in the Discipline: A Web-Based Reciprocal Peer Review System. Computers \& Education 48(3), 409-426 (2007)

6. Cho, K., Schunn, C.D., Charney, D.: Commenting on Writing: Typology and Perceived Helpfulness of Comments from Novice Peer Reviewers and Subject Matter Experts. Written Communication 23(3), 260-294 (2006)

7. Cho, K., Schunn, C.D., Kwon, K.: Learning Writing by Reviewing (under review)

8. Cho, K., Schunn, C.D., Lesgold, A.: Comprehension Monitoring and Repairing in Distance Collaboration. In: the Proceedings of the 24th Annual Conference of the Cognitive Science Society. Erlbaum, Mahwah New Jersey (2002)

9. Cho, K., Schunn, C.D., Wilson, R.: Validity and Reliability of Scaffolded Peer Assessment of Writing from Instructor and Student Perspectives. Journal of Educational Psychology 98(4), 891-901 (2006)

10. Crampton, C.: The Mutual Knowledge Problem and Its Consequences for Dispersed Collaboration. Organization Science 12(3), 346-371 (2001)

11. Falchikov, N.: Improving Feedback to and from Students. In: Knight, P. (ed.), Assessment for Learning in Higher Education. pp. 157-166. Kogan Page, London, (1995)

12. Haswell, R.H.: NCTE/CCCC's Recent War on Scholarship. Written Communication 22, 198-223 (2005)

13. Johnson, D.W., Johnson, R.T.: Cooperation and Competition: Theory and Research. Interaction Book Company, Edina MN (1989) 
14. Johnson, D.W., Johnson, R.T.: Cooperation and the Use of Technology. In: Jonassen, D.H. (ed.) Handbook of Research on Educational Communications and Technology, pp. 785-811. Lawrence Erlbaum Associates, Mahwah New Jersey (2004)

15. Kiesler, S. (ed.): Culture of the Internet. Lawrence Erlbaum Associates, Mahwah New Jersey (1997)

16. Lin, S.S.J., Liu, E.Z.F., Yuan, S.M.: Web-Based Peer Assessment: Does Attitude Influence Achievement? IEEE Transactions on Education 4(2), 211 (2001)

17. McDowell, L.: The Impact of Innovative Assessment on Student Learning. Innovations in Education and Training International 32, 302-313 (1995)

18. Rushton, C., Ramsey, P., Rada, R.: Peer Assessment in a Collaborative Hypermedia Environment: A Case Study. Journal of Computer-Based Instruction 20, 75-80 (1993)

19. Topping, K.: Peer Assessment Between Students in Colleges and Universities. Review of Educational Research 68(3), 249-276 (1998)

20. Topping, K.J., Smith, E.F., Swanson, I., Elliot, A.: Formative Peer Assessment Of Writing Between Postgraduate Students. Assessment and Evaluation in Higher Education 25(2), 149-166 (2000)

21. Zhao, Y.: The Effects of Anonymity on Computer-Mediated Peer Review. International Journal of Educational Telecommunications 4(4), 311-345 (1998) 